\title{
Potencialidades da Tecnologia Touchscreen para o Ensino de Matemática
}

\author{
Dircilene Val Ferreira Tostes \\ Universidade Federal Fluminense \\ Instituto do Noroeste Fluminense de Educação Superior - INFES \\ dircileneval.tostes@ hotmail.com

\section{Marcelo de Oliveira Dias} \\ Universidade Federal Fluminense \\ Instituto do Noroeste Fluminense de Educação Superior - INFES \\ marcelo_dias@id.uff.br
}

\begin{abstract}
Resumo
O uso das tecnologias digitais vem sendo cada vez mais inserido na dinâmica da sala de aula. Relata-se aqui a inserção destes recursos na prática docente/discente, abrindo possibilidades para a construção do conhecimento, para uma efetiva produção colaborativa, promovendo a compreensão do conhecimento construído, além de analisar os resultados dessa prática e tornar as aulas mais dinâmicas. Este artigo aborda a relevância da utilização de dispositivos com tecnologia touchscreen, os celulares (smartphones) nas salas de aula, como recurso pedagógico, apresentando alguns dispositivos disponíveis e suas características. Para desenvolver as habilidades do conteúdo de Geometria Analítica, o texto traz exemplos de atividades nas quais os alunos são orientados a instalarem em seus celulares, alguns softwares, para, nas palmas das mãos, realizarem as tarefas. Destaca-se o processo de avaliação e execução de atividades o uso do Complemento Flubaroo, utilizado para realizar as correções e análises de resultados. Ressalta-se a interação e cooperação entre discentes e docentes na construção do conhecimento, sendo estes os mediadores em todas as etapas.
\end{abstract}

Palavras-chave: Construção do conhecimento. Dispositivos. Interação.

\section{Potentials of Touchscreen Technology for Mathematics Teaching}

\begin{abstract}
The digital technologies uses are present in the dynamics of the classroom. The insertion of these resources in the teaching/learning practice is reported here, opening possibilities for the construction of knowledge for an effective collaborative production, promoting the understanding of the constructed knowledge, besides analyzing the results of this practice and making classes more dynamics. This article discusses the relevance of the use of devices with touchscreen technology, smartphones in classrooms, as a pedagogical resource, presenting some available devices and their characteristics. To develop the skills of Analytical Geometry content, the text brings examples of activities where students are instructed to install some applicative softwares on their cell phones to perform the activities on the palms of their hands. The use of the Flubaroo plugin, used to make the correction and analysis of results, also highlighed the process of assessment
\end{abstract}


and execution of activities. The interaction and cooperation between students and teachers in the construction of knowledge are emphasized, and teachers are the mediators in all stages.

Keywords: Construction of knowledge. Devices. Interaction.

\section{Introdução}

A utilização das tecnologias no ensino da Matemática é assunto bastante discutido, principalmente nas últimas décadas, visto que o uso das mídias influencia a formação dos alunos. A aprendizagem tem se tornado móvel, dinâmica, exigindo novas práticas, porém os recursos tecnológicos ainda são pouco explorados no âmbito pedagógico. Há, como afirmam Javaroni et al, um "descompasso entre a integração das tecnologias digitais no ambiente escolar e a prática das aulas de Matemática para estudantes." (JAVARONI; ZAMPIERI; OLIVEIRA, 2014, p. 970). Trazer essas ferramentas para o contexto da sala de aula e relacioná-las ao conteúdo a ser estudado pode aproximar os alunos da escola, tornar o aprendizado dinâmico e significativo, abrindo possibilidades de construção do conhecimento.

Os nascidos nas décadas 80/90, segundo Oliveira ${ }^{1}$ (2009, apud, Burgos; Sena, 2010, p. 4), chamados "Young Generation" ou "Geração Y", são indivíduos capazes de realizar muitas coisas ao mesmo tempo: os multi-tarefas. A geração de hoje se encontra num estágio ainda mais avançado, para a qual, a escola tradicional perde a sua atratividade se não estiver inserida nesse contexto. Nessa perspectiva, o presente artigo, um projeto de dissertação ainda incipiente e em desenvolvimento do Programa de Pós Graduação em Ensino (PPGEn) - UFF/Infes, relata algumas práticas que podem auxiliar professores no uso da tecnologia, a fim de estabelecer dinamicidade ao trabalhado docente e no processo de ensino e aprendizagem matemática.

São relatadas algumas práticas utilizando a tecnologia digital móvel, dispositivos com tecnologia touchscreen nas aulas de Matemática, abordando conteúdos de Geometria Analítica, com o objetivo de promover a interação, incentivar a criatividade e a descoberta de novas formas de construções geométricas. Fazemos uso de uma metodologia qualitativa participativa, a qual permite uma atuação efetiva dos estudantes, valoriza seus conhecimentos e experiências, envolvendo-os numa discussão crítica acerca dos conhecimentos construídos. Pretendemos, ao final da pesquisa, responder às questões: É possível produzir, interagir e integrar-se, criando novos significados a partir dos conteúdos estudados? De que modo os dispositivos com tecnologia touchscreen alteram

\footnotetext{
${ }^{1}$ Sidnei Oliveira. Geração Y - Era das conexões: tempo de relacionamentos. Editora: Clube de Autores. 2009 , 210 páginas.
} 
as relações entre os alunos e o saber? A necessidade que a sociedade tem de informação e atualização requer uma nova pedagogia de ensino?

\section{Tecnologia Touchscreen no Ensino da Matemática}

"Uma das maneiras de colocar literalmente a matemática na ponta dos dedos é a utilização dos aplicativos em tablets e iPads" (BAIRRAL et al, 2015, p. 33), destacando também os celulares smartphones. A tecnologia touchscreen possibilita toques e manuseios na tela, envolve percepções físicas, proporcionando que os alunos sejam agentes na construção de seus conhecimentos, possibilitando a compreensão desse conhecimento de forma dinâmica. Alguns softwares apresentam diferentes representações de um mesmo objeto interagindo entre si, tornando dinâmica a pesquisa ou a realização das atividades.

Vale lembrar que o uso dos telefones celulares nas escolas é proibido segundo a Lei Estadual, do Rio de Janeiro, № 5222, de 11 de abril de 2008 e sua Ementa - Nova redação dada pela Lei $\mathrm{N}^{\circ}$ 5453, de 26 de maio de 2009, "fica proibido o uso de telefones celulares nas salas de aulas e outros espaços de estudos, por alunos e professores da rede pública estadual de ensino, salvo com autorização do estabelecimento de ensino, para fins pedagógicos", ou seja, faz menção ao uso inadequado do celular nas escolas, que prejudica a aprendizagem e a disciplina neste ambiente, sendo permitido o uso como recurso pedagógico. Se o celular não é utilizado de maneira correta, cabe ao professor e à comunidade escolar, "educar os alunos de forma a integrar essa tecnologia móvel à cultura escolar e ao material didático.” (BORBA; LACERDA, 2015, p. 501).

Com o propósito de somar o uso de tecnologias móveis como mais uma possibilidade de recursos didáticos, o professor de Matemática, a partir das habilidades a serem desenvolvidas, orienta os alunos a instalarem em seus dispositivos móveis - celulares -, os aplicativos gratuitos que permitem experimentar de maneira relevante, os recursos de geometria e álgebra, através dos conteúdos de Geometria Analítica a serem trabalhados: marcação de pontos no plano, observação, na janela de álgebra, da distância entre os respectivos pontos, construção de retas e circunferências, indentificando suas equações. Vale ressaltar que para utilizar os softwares apresentados pode-se estar off-line, sendo necessária a conexão com a Internet apenas para instalá-los.

Os conteúdos são trabalhados na sala de aula, dispondo de livro didático, caderno, papel quadriculado, lápis, borracha. São realizados cálculos utilizando fórmulas ou a dedução das mesmas, também de forma concreta, permitindo que cada aluno construa seu conhecimento e chegue às respostas das atividades propostas. É importante salientar que os softwares são apresentados aos alunos e trabalhados depois eles têm essa prática com os cálculos relacionados aos conteúdos. 
O trabalho pode ser desenvolvido na sala de aula, com vários softwares, dentre eles, o Graphing Calculator (GeoGebra para dispositivos móveis), MyScript Calculator e Sketchometry. A realização de tarefas por manipulação de dispositivos com tecnologia touchscreen é diferente da realizada por mouse - clicar e arrastar -, como na geometria dinâmica. As manipulações touchscreen surgem a partir da percepção e do controle motor. Os movimentos são associados ao modo de tocar a tela durante a construção geométrica. Observam-se movimentos matemáticos conhecidos (clicar, girar, transladar), mas, “especificamente, estamos interessados nos modos de manipulação touchscreen e na identificação de estratégias de raciocínio dos discentes que podem estar associadas aos diferentes modos de tocar uma tela.” (BAIRRAL, 2013).

A familiaridade dos alunos com esses recursos e sua utilização de forma adequada pode promover a aproximação e desenvolvem laços de confiança e segurança por ambas as partes, dão espaço a conversas informais e tutoria por parte dos próprios alunos, interferindo na qualidade da atividade, potencializando a interação e troca de experiências. A informação apresentada pelas tecnologias ultrapassa a linguagem verbal, comumente usada no ambiente escolar, amplia possibilidades de estímulos simultâneos - multissensoriais -, e promove o senso de investigação, expandindo a capacidade comunicação entre professores e alunos. Segundo Ponte (2000), as TIC podem contribuir para uma educação mais adequada à nossa sociedade, possibilitando a criação de espaços de interação e comunicação. Nessa perspectiva, cabe ao professor traçar objetivos e selecionar os instrumentos que melhor se enquadrem na realidade de seus alunos.

Moran (2000, p. 63) nos traz o seguinte apontamento:

Ensinar com as novas mídias será uma revolução se mudarmos simultaneamente os paradigmas convencionais do ensino, que mantêm distantes professores e alunos. Caso contrário, conseguiremos dar um verniz de modernidade, sem mexer no essencial. A internet é um novo meio de comunicação ainda incipiente, mas que pode nos ajudar a rever, a ampliar e a modificar muitas das formas atuais de ensinar e de aprender.

A relação professor aluno estreita-se, à medida que se deixam envolver pela interação que os próprios recursos tecnológicos proporcionam. A constante evolução tecnológica implicará numa constante revisão da prática de ensinar e de aprender.

\section{Softwares abordados: Graphing Calculator}

O software Graphing Calculator, consiste numa calculadora científica para Android, adequado para construções rápidas, e tem a vantagem didática de apresentar, ao mesmo tempo, representações diferentes de um mesmo objeto que interagem entre si, mostradas através da janela algébrica, com a exibição da equação ou procedimento realizado e da janela geométrica. 
O software é utilizado pelos alunos, através de simples toques na tela dos aparelhos de celular, para executar tarefas orientadas pelo professor, tornando possível, através do celular, executar tarefas disponíveis como no GeoGebra: usar a barra de ferramentas, marcar pontos no plano, observá-los na janela algébrica, traçar segmentos de retas unindo-os para obter a medida dos segmentos, medir a distância entre os respectivos pontos, construir retas e circunferências, indentificando suas equações. A Figura 1 apresenta algumas imagens de telas de celular, como dados da pesquisa, mostrando pontos, suas coordenadas e a distância entre pontos, determinada por segmentos de retas.

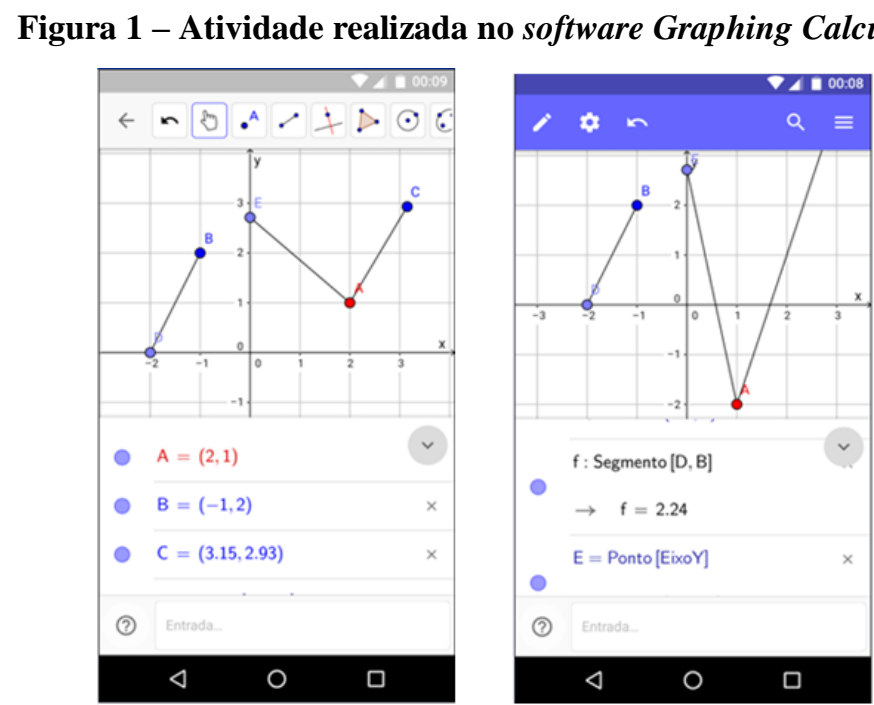

Fonte: Template do software Graphing Calculator .

A barra de ferramentas, mostrada nas imagens dispõe de recursos variados para as construções geométricas. Seguem, na Figura 2, a construção de reta, circunferência e observação de suas respectivas equações:

Figura 2 - Atividade realizada no software Graphing Calculator
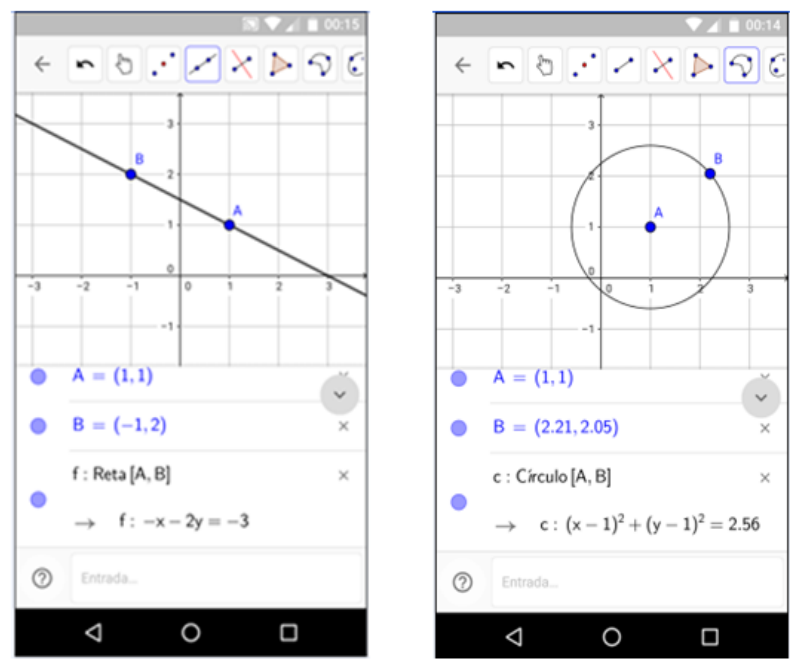

Fonte: Template do software Graphing Calculator. 


\section{MyScript Calculator}

Software também projetado para dispositivos Android. Para se construir um objeto, precisa realizar apenas movimentos específicos na tela, deslizando o dedo sobre ela, escrevendo a expressão matemática com a própria caligrafia. Não apresenta barra de ferramentas elaborada ou teclado, pois utiliza o manuscrito para escrever e calcular expressões matemáticas, com as operações básicas, de uma forma intuitiva e natural, como exibido na Figura 3.

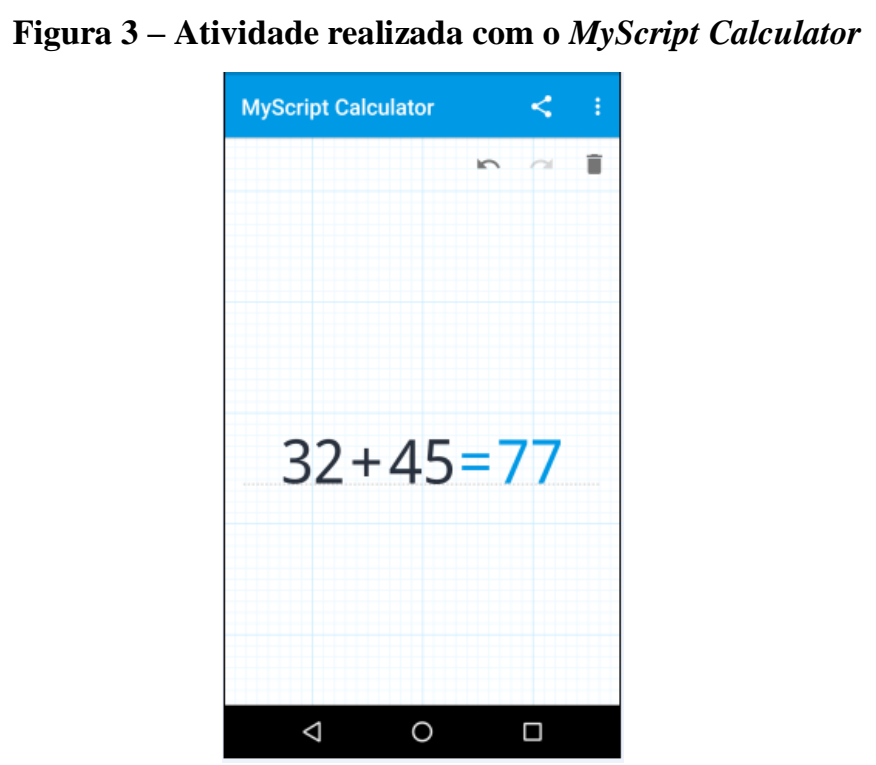

Fonte:Template do software MyScript Calculator.

A figura 3 mostra uma atividade simples em que o aluno desliza o dedo pela tela do software MyScript Calculator, iniciando uma operação de soma de números naturais, podendo esta ser traçada de uma só vez ou em etapas. As sentenças matemáticas ou cálculos criados neste aplicativo terão o resultado fornecido imediatamente se estiver ativado o cálculo automático. Caso seja necessário mais tempo para escrever o cálculo, basta desativar o cálculo automático e usar o botão "Calcular", para que o mesmo seja exibido. Observa-se que este recurso não apresenta barra de ferramentas e reconhece poucos símbolos e caracteres, evidenciando a manipulação e movimentação dos dedos pela tela, proporcionando ao aluno, a liberdade de criação.

\section{Sketchometry}

Com o terceiro software citado, Sketchometry, as construções acontecem através de toques simples e também da combinação de movimentos ou manipulações que surgem a partir das simulações perceptivas e motoras, permitindo aos alunos a construção e a investigação de conjecturas matemáticas, particularmente no que diz respeito às concretizações mentais e à formulação do 
pensamento, construindo o conhecimento diferente da representação estática, realizada no caderno.

A figura 4 apresenta uma tela de celular, na qual foi criada uma circunferência, deslizando o dedo sobre ela, em movimento circular.

Figura 4 - Atividade realizada com o Sketchometry

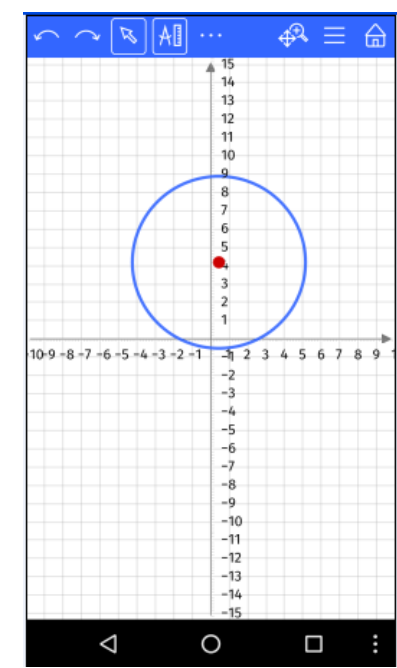

Fonte: Template do Software Sketchometry.

Trabalhar a matemática com o uso da tecnologia digital móvel é uma realidade que permite acesso imediato aos dados, o divertimento e a possibilidade de aprender em diferentes contextos, vivenciando novas formas de demonstração, estimulando o pensamento e a argumentação matemática, ampliando os espaços de aprendizagem.

Vale lembrar que os softwares citados neste artigo não precisam de Internet para funcionar, apenas no momento da instalação que ela se faz necessária. Para contornar problemas que possam surgir com as limitações dos dispositivos, novas estratégias e planejamentos devem ser elaborados.

\section{Dispositivos Touchscreen no Processo Avaliativo}

A avaliação é um dos maiores desafios da educação e deve ser pensada de forma dinâmica e interativa, pensada também como um processo formativo que serve para compartilhar, comunicar e intercambiar de forma colaborativa (PENCINATO; FETTERMANN; OLIVEIRA, 2016, p. 91). Dessa maneira, considera-se que existe uma reflexão constante em relação ao aprendizado e aos objetivos alcançados. Pesquisas indicam que as orientações sobre o uso de tecnologias revelam dificuldades de sua incorporação na prática, pois essas recomendações pressupõem uma mudança de paradigma referente à maneira de conceber a matemática e seu ensino (DIAS, 2016, p. 233). Portanto, novas formas de avaliar são pensadas com frequência, visando impedir que o aluno se sinta pressionado para a realização avaliativa. As avaliações e atividades feitas através dos 
dispositivos móveis de tecnologia touchscreen - os celulares -, têm um caráter formativo e podem deixar o aluno mais tranquilo considerando sua familiaridade com esses aparelhos.

Diversas pesquisas vêm comprovando a eficácia do uso das tecnologias da informação e comunicação nos ambientes educacionais, demonstrando que os professores têm ao seu alcance formas de vislumbrar o processo de ensino e aprendizagem em suas práticas (PENCINATO; FETTERMANN; OLIVEIRA, 2016, p. 94). Este artigo enfatiza o Flubaroo como um instrumento de avaliação, o qual permite que elas sejam realizadas, nas palmas das mãos, sendo organizadas em Formulários Google, com o complemento de correção, dinamizando a organização do trabalho docente, pois auxilia a avaliação de respostas, faz sua correção automática e avaliação através de planilhas e gráficos apresentados ao professor, e, principalmente, auxilia o aluno no seu desenvolvimento cognitivo, possibilitando verificar progressos e dificuldades.

Depois de organizadas as avaliações ou atividades objetivas nos Formulários Google, o link de cada uma é enviado para os alunos pelo WhatsApp ou por e-mail, ficando a critério do professor a melhor forma de envio. Os alunos respondem a cada questão através do celular, com simples toques na tela. Após responderem, enviam e tem-se a conclusão deste processo avaliativo, pois a correção se dá de forma automática. Cabe, em seguida, fazer a análise dos resultados obtidos, através de uma reflexão crítica.

Conforme salientam Pencinato, Fettermann e Oliveira (2016, p. 99),

Desta maneira, pode-se acompanhar o desempenho de cada um de forma mais rápida e eficaz, possibilitando identificar dificuldades e pensar em uma solução para, então, dar um retorno para os estudantes, que lhes permita buscar conhecimento e aperfeiçoar as habilidades nas disciplinas estudadas.

Professores e alunos se beneficiam com esse feedback imediato, aproveitando a oportunidade para refletirem criticamente sobre os resultados obtidos. Na sala de aula, podem tirar dúvidas quanto aos erros cometidos, compartilhando a construção de saberes coletivamente. Portanto, o educador não pode se apoiar nas ferramentas tecnológicas, esquecendo-se de que ele é o facilitador e mediador na construção de conhecimentos no decorrrer de suas aulas. Ele deve propiciar "que os aprendizes ocupem papel ativo, crítico, social e colaborativo" no processo avaliativo (OKADA, 2011, p. 12).

A Figura 5 mostra duas telas de celular de uma avaliação organizada e enviada para os alunos via WhatsApp, a ser realizada na sala de aula. A primeira imagem apresenta o cabeçalho da avaliação, onde são observados os itens assinalados como obrigatórios e, a segunda, com uma da questão do conteúdo de Geometria Analítica. 


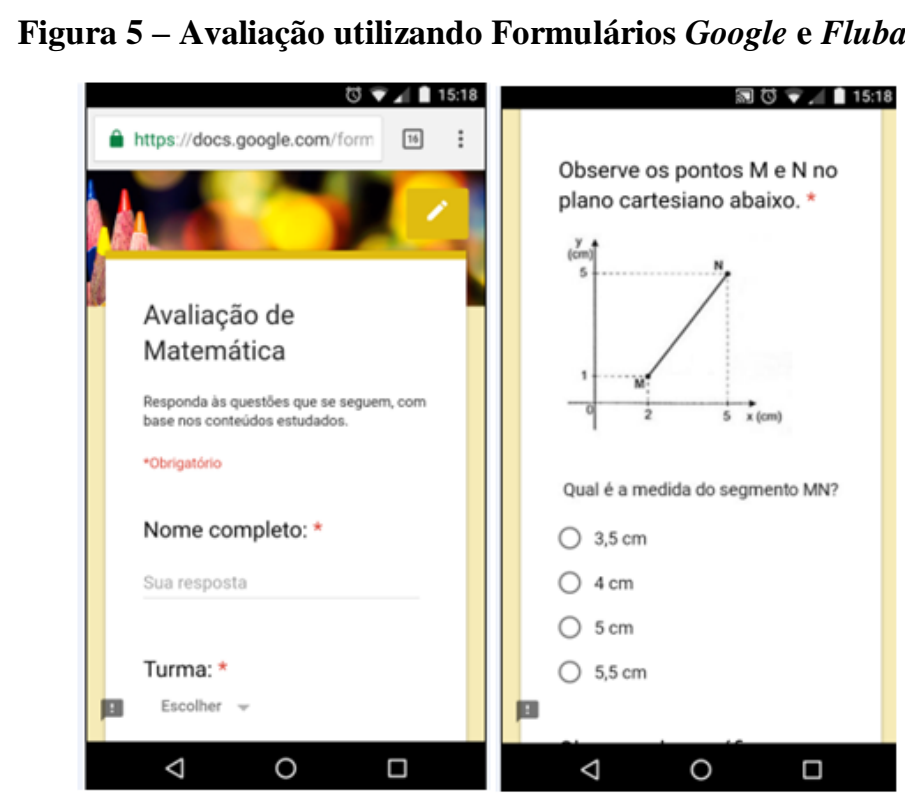

Fonte: Template de um Formulário construído no Google.

Todos os itens do formulário avaliativo devem ser respondidos com simples toques na tela touchscreen. Lembrando que, para se resolver essa questão, o aluno tem o prévio conhecimento do cálculo da distância entre dois pontos, aplica a fórmula resolvendo a raiz quadrada e chega ao resultado final; depois então é que, com simples toque na tela do celular ou outro dispositivo móvel que esteja usando, ele vai assinalar a opção correta. Após responder a todas as questões, o formulário de avaliação é enviado para o professor. Sendo formulário online, para se trabalhar é necessário estar conectado a Internet.

Como já foi mencionado anteriormente, a correção se dá de forma automática e é gerada a planilha de respostas, na qual é possível observar a data e o horário em que cada aluno enviou a atividade, suas respostas, o número e o percentual de acertos de cada aluno, além do percentual de acertos de cada questão. As questões nas quais os alunos não alcançaram 50\% de desempenho são destadacas, informando as habilidades não construídas, para que possam ser revistas e trabalhadas novamente, com o objetivo de se alcançar o resultado desejado.

\section{Considerações Finais}

As reflexões desenvolvidas ao longo deste artigo mostram que a presença dos aparelhos digitais móveis, principalmente os celulares, nas salas de aula é uma realidade que está sendo trabalhada de forma a inseri-los como prática pedagógica a favor da educação, trazendo novos desafios às escolas atuais, tornando impossível dissociar a tecnologia da escola, pois ela supre na sociedade, a necessidade de uma constante atualização. Ressalta-se a importância da tecnologia na produção de conhecimento matemático, propiciando novas construções e abordagens a partir dos conteúdos estudados. Os estudantes se sentem motivados a realizar as tarefas propostas quando têm a opção 
de se trabalhar com as tecnologias digitais móveis, no processo de aprendizagem, atrelando-as ao currículo estudado, pois promovem a interação e a colaboração, apresentam vantagens relacionadas ao conteúdo, incentivando às construções geométricas.

Observa-se também que há desenvolvimento individual e coletivo através das relações estabelecidas, respeitando o pensar e o fazer matemático de cada um, enfatizando a compreensão e a aplicabilidade de conceitos ligados ao uso de tecnologias, sobre suas potencialidades e limitações. Este processo de construção e compreensão do conhecimento, é visto como essencial ao desenvolvimento pleno do estudante em todas as áreas.

A partir das experimentações iniciais, outras questões serão levantadas, implementações e estudos serão realizados e discutidos. É possível ressaltar a interação e cooperação entre docente e discentes na construção do conhecimento, salientando a importância da disposição do professor ao inserir no planejamento de suas aulas os recursos tecnológicos que podem auxiliar na aprendizagem, consolidando conceitos e criando meios para proporcionar o desenvolvimento da aprendizagem do conteúdo, contribuindo para a motivação do estudante.

As atividades sugeridas proporcionam oportunidades de verificação, de avanços e desafios que ocorrem na sala de aula com a exploração dos softwares, através da possibilidade de criação de objetos, permitindo ao aluno criar, comparar figuras e relacioná-las a sua representação algébrica, relacionando-as aos desenhos geométricos e com os cálculos feitos no material didático, através de fórmulas e deduções. Cada dispositivo possibilita que os alunos tenham ações e interações diferenciadas, além de desenvolverem o raciocínio e a aprendizagem.

A utilização dos recursos tecnológicos no ensino da Matemática não garante a inovação dos processos educacionais, mas pode trazer a possibilidade de desenvolvimento profissional docente, no qual será possível rever as práticas e analisar/criar modelos matemáticos que atendam à demanda atual sobre a necessidade constante de se repensar e se refazer a prática educativa.

\section{Referências}

BAIRRAL, M.; ASSIS, A.; SILVA, B. C. (Orgs.) Mãos em ação em dispositivos touchscreen na educação matemática. 1ªed. v.7, Rio de Janeiro: Ed. da UFRRJ, 2015 (série InovaComTic).

BAIRRAL, M. A. (Org.). Tecnologias Informáticas, sala de aula e aprendizagens matemáticas, v.3, Rio de Janeiro: Ed. da UFRRJ, 2010 (série InovaComTic).

BAIRRAL, M. A. Do clique ao touchscreen: Novas formas de interação e de aprendizado matemático. Reunião anual da ANPED, v.36, p.29, Goiânia:2013.

BORBA, M. D. C.; LACERDA, H. D. G., Políticas Públicas e Tecnologias Digitais: um Celular por Aluno. Educação Matemática Pesquisa, São Paulo, v. 17, n. 3, p. 490-507, 2015. 
BORBA, M. C.; SCUCUGLIA, R. R. S.; GADANIDIS, G. Fases das Tecnologias Digitais em Educação Matemática: sala de aula e internet em movimento. Belo Horizonte: Autêntica Editora, 2014.

BORBA, M. C.; PENTEADO, M. G.- Informática e Educação Matemática, Belo Horizonte: Autêntica, 2005.

BORTOLOSSI, H. J.; REZENDE, W. M.; PESCO, D. U. Instituto GeoGebra no Rio de Janeiro. 2015, disponível em <http://www.geogebra.im-uff.mat.br> . Acesso em 30/01/2017

BURGOS, Taciana; SENA, Diana. O computador e o telefone celular no processo ensinoaprendizagem da educação física escolar. Anais Eletrônico do $3^{\circ}$ Simpósio Hipertexto e Tecnologia na Educação: redes sociais e aprendizagem. Recife: Universidade Federal de Pernambuco, 2010.

CONTIERO, L. O.; GRAVINA, M. A. Modelagem com o Geogebra: uma possibilidade para a educação interdisciplinar?, Revista Renote, julho. Vol. 9, número 001. Porto Alegre, 2011, disponível:file:///C:/Documents\%20and\%20Settings/nLite/Meus\%20documentos/Downloads/2191 7-80609-1-SM.pdf , acesso em: 17/01/2017.

DIAS, M. O. Tendências em Educação Matemática: Percursos curriculares brasileiros e paraguaios, 1. ed. Curitiba: Appris, 2016.

FARIA, R. W. S. Padrões fractais: contribuições ao processo de generalização de conteúdos matemáticos. 2012.

JAVARONI, S. L.; ZAMPIERI, M. T.; OLIVEIRA, F. T. Tecnologias digitais: É possível integrá-las às aulas de Matemática? In: Congresso Internacional das TIC na Educação, III., 2014, Lisboa. Anais... Lisboa: Instituto de Educação da Universidade de Lisboa, 2014. p. 970-974.

MORAN, J. M. Novas tecnologias e mediação pedagógica. Campinas. SP: Papirus, 2000.

OKADA, A. Colearn 2.0 - Coaprendizagem via comunidades abertas de pesquisa, práticas e recursos educacionais. Revista E-curriculum, v. 7, n.1, 2011.

OLIVEIRA, S. Geração Y - Era das conexões: tempo de relacionamentos. Editora: Clube de Autores. 2009.

PENCINATO, G. S.; FETTERMANN, J. V ; OLIVEIRA, D. M. A. Avaliação da Aprendizagem de Línguas através de Tecnologias Educacionais: o Flubaroo em foco. In: FETTERMANN, J. V;

CAETANO, J. M. P. (Orgs) Ensino de línguas e novas tecnologias: diálogos interdisciplinares. Campos dos Goytacazes, RJ: Brasil Multicultural, 2016.

PONTE, J. P. Tecnologias de Informação e Comunicação na Formação de Professores: Que Desafios? Revista Iberoamericana de Educación, 24, set/dez: 63-90, 2000.

RHENIUS, A.; MEIER, M.; BASSO, M. V. A. O Sketchometry e a utilização de tecnologias Toutchscreen na Geometria Dinâmica. TISE, v.11, p.754-758, 2015, disponível em < www.tise.cl/volumen11/TISE2015/754-758.pdf>. Acesso em 30/11/2016.

RIO DE JANEIRO, Lei n ${ }^{\circ}$ 5222, de 11 de abril de 2008. Disponível em: https://goo.gl/zFhDMG, acesso em 10/06/2016.

RIO DE JANEIRO, Lei no 5453, de 26 de maio de 2009. Disponível em: https://goo.gl/sjZbzr, acesso em 10/06/2016. 